\title{
Sanrachna
}

\section{ORPHAN DRUG POLICY}

\section{Objective}

To look at existing Orphan Drug Policies and how we can aim at making it more equitable in India.

\section{Method}

Research is completely based on secondary data from online journals and government data. The study is analytical in its approach and is descriptive in nature.

\section{Introduction}

Millions of people in developing countries do not have access to health care services and medications which are available in developed countries. Most of the rare diseases are genetic in nature. They disproportionately impact children: $50 \%$ of new cases are in children and are responsible for $35 \%$ of deaths before the age of 1 year, $10 \%$ between the ages of 1 and 5 years and 12\% between 5 and 15 years (Ministry of Health and Family Welfare, 2017, p.9). However, the most neglected diseases by pharma industries are tropical diseases that are caused by parasites and spread by insects or contaminated water or soil for example (Saviano, Barile, Caputo, Lettieri and Zanda, 2019). Development of Orphan drug policies are least concern of pharmaceutical companies. They work on the calculation of number of vaccines manufactured on cost of per vaccination. Market is a precious venture for pharmaceutical companies. They are hesitant on the sale of the product. Development of such drugs rely heavily on Intellectual Property Rights in order to ensure the return of money invested on it. However, in India TradeRelated Aspects of Intellectual Property Rights (TRIPS) has been introduced but has not been enforced as big companies provide medicines at cheap prices (The Portal for Rare Diseases and Orphan Drugs, 2020). Therefore, the paper try looking at policies that can make pharma companies to invest more on the research of orphan drugs.

\section{Discussion}

Rare diseases are chronic and life-threatening illness that require proper long-term medical treatment. As these diseases are rare so the development of medication requires high amount of fund which affect the family of a patient suffering from rare disease. Thus, Government of India asked Ministry of Health and Family Welfare to draft a policy on treatment of rare disease because of the above-mentioned reasons. So, the Ministries looked at multisectoral approach to prepare India to tackle the problem of rare disease in areas like estimating the number that can affect or had affected the person, research on medication and diagnostic of disease, awareness, training of health caregivers and affordability of treatment. Government of India, recommend policies which mark a balance between the affordability of treatment and sustaining of medical research centres. This paper also mark a shift from health economics to mangerial perspective by looking at societal values of orphan drugs in a realm of sustainable development from two categories 1 . Social equality and 2 . Inclusiveness perspective through the example of Covid-19. 


\section{Sanrachna}

If we apply international estimation of $6 \%$ to $8 \%$ people getting affected by rare disease then in India it has affected 72 to 96 million people which is a significant number (Ministry of Health and Family Welfare, 2017, p.9). The economic burden in such scenarios for rare diseases left unknown which puts a challenge in estimating the funds required for research.

However, Dyfrig A. Hughes professor at Bangor University stated in his study that companies with orphan drug authorization have more investment and profitable opportunities that non orphan drugs; as incentives related to research reduce marketing cost and premium pricing. In support to the argument orphan drug market grow at a compound annual growth rate (CAGR) (Sharma, Jacob, Tandon, and Kumar, 2010). The market is expected to reach $\$ 178$ billion by 2020 and and account for 19\% of total branded prescription drug sales (Hughes, 2016).

The major pharmaceutical sales orginate from US, EU and Japan. Together they account for $80 \%$ of global market. U.S itself accounts for $45 \%$ of pharmaceutical sales, then Europe $24 \%$ and Japan $11 \%$. Further, the cost of treatment and medication is much expensive in U.S; and Orphan Drug cost per patient in U.S is 4.5 times higher than non orhpan drug cost. In recent times the median between the price of orphan and non- orphan is reduced by $50 \%$ in U.S. This shows market exclusivity. Companies working on coronavirus treatment are registered as rare disease treatment with US regulatory, a status which is worth million in tax breaks. Celgene, Abbvie, Johnsons \& Johnsons are the leading companies of orphsn drug market (Pomeranz, 2019 , p.7). Gilead Sciences comes on $13^{\text {th }}$ position accounting for $\$ 0.4$ billion worldwide orphan drug sale in 2018 with $0.7 \%$ market share. They have been successful in making an experimental drug Remdesivir for treating coronavirus and have also taken permission from Food and Drug Administration to use it on patients suffering From Covid-19. In addition more than 50 drugs have been made to cure coronavirus patients worldwide. The emergency for inventing a vaccince for covid-19 is because it has spread across borders, including countries with poor health system.

In India to stimulate research regarding rare diseases and development of its medication authorities and ministries have incentivised biotechnology and health industries. To accelerate the research countries in incentivisation have included tax benefits and increased the period of market exclusivity to maintain the interest of pharmaceutical companies. $70 \%$ of domestic demand for bulk drugs is delievered by the Indian pahrmaceutical industries. With $40 \%$ of total pharmaceutical products are exported out of which $55 \%$ of total export constitute formulation and $45 \%$ copnsists of bulk drugs. 'The Indian Pharmaceutical Industry is one of fastest emerging international center for contract research and manufacturing services or CRAMS'. The reason for it emergence is internation high quality with low cost. India has biggest number of US food and drug administration. The manufacturing cost of drugs is half of the price than in U.S., and the cost incurring for research is eigth times more in U.S. This indicates India's service deliverance globally at lower cost.

It is crucial for Indian pharmaceutical companies to work in collaboration with U.S registered rare treattment pharma companies as there market investment will help Indian pharma companies to conduct resarch and develop vaccines at lower price. However, policy is always made with an understanding that people will look for good healh care and services. Pricing of medicines is crucial for consideration while developing a policy. Lower cost will directly affect 


\section{Sanrachna}

the cost of the treatment. Also, product patent has been introduced in the country. Also, a 'Pharmaceutical Research and Development Support Fund (PRDSF) with a corpus of Rs.150 crores have been set up under the administrative control of the Department of Science and Technology' (Akhtar, 2013, p.54). in order to encourage pharma companies to work upon orhan drugs it is important to increase time for renewal of orphan drug for example, person who is eligible for grants for exmaple in Japan orphan drug applicant recieves consultation from ministry of Health, Labor and Welfare for free, increase in time period of product renewal for orphan drug, government support doctors to use the product. (Sharma, Jacob, Tandon, and Kumar, 2010).

Government has always allowed smooth functioning of pharma companies. These pharma companies have enjoyed trade surplus since 1987, because of which it was expected that indian pharma companies will increase the manufacturing of generic drugs worldwide. Their effort to increase export some of the pahrma companies have esatblisehed their marketing and trade supporting centers in developed countries and launched generic segments as cheaper alternatives to branded products. At national level, As policy making ought to involve level of ministries it is highly recommended to look upon the smooth implementation mechanism. For example- corpus funds should not only be made available by Center and the State government but also by local authorities for easy access by local health centres. Also, government need to set up its own diagnostic laboratories and research departments to create epidemiological data. Better infrastructure leads to a development of the department. More focus need to have on biogenerics as they account for $50 \%$ of orphan drug market globally. Also revision on drugs and there usage need to be done ${ }^{1}$. All these recommendations can help in striking a balance between pharmaceutical companies to work for orphan drug.

\section{Conclusion}

The scenario of orphan drugs stands differently in developing countries like India than in developed countries. The issue is approached differently as nature of this practice is linked with high costs with fewer returns. Government approach to it through incentivisation has led a paradigm shift in pharmaceutical companies towards orphan drugs. Nevertheless, the lack of interest of Indian medical institutions towards orphan drugs has led poor awareness among public. To tackle this government not only established legislation but took extra effort of providing corpus fund which reduce premium pricing of drugs. However, working with companies worldwide will help in dvelopment of medicines at lower cost.

\section{References}

Akhtar, Gulshan. 2013, Indian Pharmaceutical Industry: An Overview, IOSR Journal Of Humanities And Social Science (IOSR-JHSS), 11(3), pp.51-66, Available from: http://www.iosrjournals.org/iosr-jhss/papers/Vol13-issue3/H01335166.pdf?id=3395

\footnotetext{
${ }^{1}$ Products withdrawn from the market for economic or therapeutic reasons. Few drugs which are withdrawn from the market for some reasons, e.g., thalidomide widely used as a hypnotic drug some years ago for its high teratogenic (triggering fetal malformations) risk may show a very interesting therapeutic application, i.e., analgesic proprieties in rare diseases such as leprosy and lupus erythematosus. These are diseases for which no satisfactory treatment is available (Sharma, Jacob, Tandon, and Kumar, 2010).
} 


\section{Sanrachna}

Anon. 26/04/2020. The Portal for Rare Diseases and Orphan Drugs. Accessed from: https://www.orpha.net/consor/cgibin/Education_AboutOrphanDrugs.php?lng=EN\&stapage= ST_EDUCATION_EDUCATION_ABOUTORPHANDRUGS_TWC

Dharssi, Safiyya et al; Wong-Rieger, Durhane; Harold, Matthew and Terry, Sharon. 2017, Review of 11 national policies for rare diseases in the context of key patient needs, Accessed from: https://www.ncbi.nlm.nih.gov/pmc/articles/PMC5374691/

GOVERNMENT OF INDIA, 2017, Ministry of Health and Family Welfare, National Policy for Treatment of Rare Diseases, pp. 1-36.

Hughes, Dyfrig A and Hughes Jannine Poletti. 2016, Profitability and Market Value of Orphan Drug Companies: A Retrospective, Propensity-Matched Case-Control Study, PLoS ONE 11(10), Available from: https://journals.plos.org/plosone/article?id=10.1371/journal.pone.0164681

Institute of Medicine (US). 2010, Committee on Accelerating Rare Diseases Research and Orphan Product Development; Rare Diseases and Orphan Products: Accelerating Research and Development, Available from: https://www.ncbi.nlm.nih.gov/books/NBK56184/

Pomeranz, Karen. 2019, Orphan Drug Report 2019, EvaluatePharma, Available from: https://info.evaluate.com/rs/607-YGS-

364/images/EvaluatePharma\%20Orphan\%20Drug\%20Report\%202019.pdf?mkt tok=eyJpIjo iWWpVMk1UVmtNRFpqT0dFeiIsInQiOiIrcmZ3QjNwamZWWVwvZ1ZkcU5XS2E3Rk5o NXA5MXZJVUVCRitMQXpQd0sxMGJPU0JhdGRWbVJQQkZrc0xZNDNPSXRNM09w MGh2OEFXNXFNN1wvb1plT

Saviano, Marialuisa; Sergio Barile, Sergio; Francesco Caputo, Francesco; Lettieri, Mattia and Stefania Zanda. 2019, From Rare to Neglected Diseases: A Sustainable and Inclusive Healthcare Perspective for Reframing the Orphan Drugs Issue, Sustainability, 11, pp.1-21.

Sharma, Arti; Jacob, Abraham; Tandon, Manas and Kumar, Dushyant. 2010, Orphan drug: Development trends and strategies, Journal of Pharmacy \& BioAllied Sciences, 2 (4), pp.290299. 